Journal of Bangladesh Academy of Sciences, Vol. 35, No. 2, 125-140, 2011

\title{
DEVELOPMENT OF STATISTICAL TECHNIQUES FOR THE FORECASTING OF NOR'WESTERS AND ASSOCIATED MAXIMUM GUSTY WIND AND RAINFALL OVER BANGLADESH
}

\author{
SAMARENDRA KARMAKAR AND MD. MAHBUB ALAM ${ }^{1}$ \\ Bangladesh Meteorological Department (BMD), Agargaon, Sher-E-Bangla Nagar, \\ Dhaka-1207, Bangladesh
}

\begin{abstract}
The forecasting techniques for the prediction of nor'westers and associated winds and rainfall have been developed. Four linear multiple regression equations for computation of maximum gusty wind speed associated with nor'westers have been developed. The computed values of maximum gusty wind speed have statistically significant correlation with the actual maximum gusty wind speed. The regression equations have been verified with data of year (2005) and will be useful for the operational meteorologists for the computations of maximum gusty wind speed associated with nor'westers. Simple linear regression equations and linear multiple regression equations have also been developed for the statistical prediction of $24 \mathrm{hrs}$ rainfall over Dhaka, country-averaged $24 \mathrm{hrs}$ rainfall over Bangladesh and $24 \mathrm{hrs}$ maximum rainfall over Bangladesh due to nor'westers. The correlation co-efficient corresponding to these regression equations are statistically significant. These equations have also been verified with the data of year 2005 .
\end{abstract}

Key words: Statistical techniques, Forecasting, Nor'westers, Bangladesh

\section{INTRODUCTION}

Nor'westers is the most frequent events during the pre-monsoon season (March-May) in Bangladesh. They are the manifestations of the instability of the troposphere where significant changes in thermodynamic characteristics take place. Because of these changes in the thermodynamic characteristics, giant cumulonimbus clouds form in the atmosphere resulting in severe thunderstorms whose fury at times is comparable with that of a tornado and cause extensive damage to property and loss of lives in Bangladesh. Sometimes, tornadoes are embedded in the mother clouds, which are produced due to the presence of greater instability and sufficient moisture influx in the troposphere. The damage is caused mainly due to maximum wind speed (MWS) associated with nor'westers/tornadoes. Not many studies have been made on the maximum peak gust associated with thunderstorms over Bangladesh and India. Pendse et al. (1967) observed that the most probable peak speed that a thunder squall at Nagpur on any day is likely to attain is in the range of $50-79 \mathrm{~km} / \mathrm{hr}$.

\footnotetext{
${ }^{1}$ Department of Physics, Khulna University of Engineering \& Technology, Khulna-9203, Bangladesh. <mdalam60@gmail.com>.
} 
The problem for the meteorologist is to determine the MWS associated with nor'westers. In Bangladesh, the meteorologists use the Tephigram analysis for the determination of maximum gust due to nor'westers following the method of Miller (1967). There is no empirical method for the determination of maximum gust due to nor'westers. It is, therefore, imperative to develop some empirical method so that the MWS associated with nor'westers can be forecasted.

During the pre-monsoon season, rainfall associated with nor'westers is very important for the agricultural activities in the country and also for the comfort of human being. Keeping in view of this fact, it is essential to develop linear multiple regression equations for the rainfall associated with nor'westers in Bangladesh.

One of the most difficult problems faced by the operational Meteorologists is whether to forecast thunderstorms/nor'westers or severe nor'westers or severe nor'westers accompanied by tornadoes. For most part, the same parameters will be present, in varying degree of intensity, for either phenomenon. Reasonable discrimination depends on certain synoptic features. The area over which nor'westers are likely to occur varies from one day to the other mostly depending on the synoptic situation at the surface and upper level. Meteorologists prepare charts of different stability indices to delineate the area of instability of the atmosphere conducive to the formation of thunderstorms. Some of the stability indices are SI, LI, DPI, DII, SWEAT, EI etc (Showalter 1953), Faubush et al. (1951), Darkow (1968), Galway (1956), Chowdhury and Karmakar (1986), Das et al. (1994), Karmakar and Alam 2006) and modified instability indices MVT, MCT, MTT, MKI, MSWI, MEI etc. (Karmakar and Alam 2007) have been computed by using the 850 and $925 \mathrm{hPa}$ levels, respectively considering as the as the low-levels. Identification of this are with positive threat of the storms is one of the difficult tasks faced by the Meteorologists. These criteria may be used as the forecasting techniques for the occurrence of nor'westers.

Attempts have been made to correlate the MWS associated with nor'wester/ thunderstorms, which occurred at Dhaka with a number of meteorological parameters in order to develop a multiple regression formula suitable for the forecasting of maximum gusty wind speed associated with nor'westers/thunderstorms. Linear multiple regression equations have also been developed for the forecasting of $24 \mathrm{hrs}$ rainfall associated with nor'westers. Attempts have also been made to verify the developed regression equations for the rainfall and the maximum gusty wind speed by using data on the dates of occurrence of nor' westers during the pre-monsoon season of 2005 and continuous data of 1 - 16 May, 2005. Synoptic and statistically techniques for the forecasting of nor'westers and associated maximum gusty wind and rainfall have been developed. 
Maximum wind speed recorded at Dhaka due to nor'westers, rawinsonde data at different isobaric height, MSL pressure at 0000 UTC on the dates of occurrence of nor'westers during the period March-May of 1990-1995 have been utilized to find out an empirical formula for the determination of maximum gusty wind speed associated with nor'westers. The rawinsonde data has been used to derive a lot of parameters with which multiple regressions have been made.

The rawinsonde data at 0000 UTC over Dhaka, maximum gusty wind over Dhaka, MSL pressure and the next 24 hours rainfall at 34 stations over Bangladesh on the dates of occurrence of several nor'westers during March - May, 2005 have been used to verify the regression equations developed, for the prediction of maximum gusty wind speed and the rainfall associated with nor'westers. The data have been collected from the Storm Warning Centre (SWC) of Bangladesh Meteorological Department (BMD).

\section{MATERIALS AND METHODS}

The maximum wind speed (MWS) and rainfall associated with nor'westers over Dhaka have been correlated with a number of parameters with a view to forecasting them by using multiple regression equation as given below:

$$
Y=a_{1}+a_{2} X_{1}+a_{3} X_{2}+a_{4} X_{3}+\ldots \ldots \ldots \ldots+a_{n} X_{n}
$$

where,

$\mathrm{X}_{1}=$ Total Totals Index (TT) over Dhaka at $0000 \mathrm{UTC}$,

$\mathrm{X}_{2}=$ Cross Total Index (CT) over Dhaka at 0000 UTC,

$\mathrm{X}_{3}=$ Vertical Total Index (VT) over Dhaka at 0000 UTC,

$\mathrm{X}_{4}=\mathrm{K}$-Index (KI) over Dhaka at $0000 \mathrm{UTC}$,

$\mathrm{X}_{5}=$ Showalter Stability Index (SI) over Dhaka at 0000 UTC,

$\mathrm{X}_{6}=$ Lifted Index (LI) over Dhaka at 0000 UTC,

$\mathrm{X}_{7}=$ Dew-Point Index (DPI) over Dhaka at 0000 UTC,

$\mathrm{X}_{8}=$ Dry Instability Index (DII) over Dhaka at 0000 UTC,

$\mathrm{X}_{9}=$ SWEAT Index (SWI) over Dhaka at 0000 UTC,

$\mathrm{X}_{10}=$ Energy Index (EI) over Dhaka at 0000 UTC,

$\mathrm{X}_{11}=$ Modified Vertical Total Index (MVT) over Dhaka at 0000 UTC,

$\mathrm{X}_{12}=$ Modified Cross Total Index (MCT) over Dhaka at 0000 UTC,

$\mathrm{X}_{13}=$ Modified Total Totals Index (MTT) over Dhaka at 0000 UTC,

$\mathrm{X}_{14}=$ Modified K-Index (MKI) over Dhaka at 0000 UTC,

$\mathrm{X}_{15}=$ Modified Severe Weather Treat Index (MSWI) over Dhaka at 0000 UTC,

$\mathrm{X}_{16}=$ Ratio of the MVT and MCT over Dhaka at 0000 UTC,

$\mathrm{X}_{17}=$ Precipitable water content $(\mathrm{W})$ over Dhaka at $0000 \mathrm{UTC}$,

$\mathrm{X}_{18}=$ Specific humidity $q_{1000}$ at $1000 \mathrm{hPa}$ level over Dhaka at $0000 \mathrm{UTC}$,

$\mathrm{X}_{19}=$ Specific humidity $q_{850}$ at $850 \mathrm{hPa}$ level over Dhaka at $0000 \mathrm{UTC}$, 
$\mathrm{X}_{20}=$ Difference between latent heat at $1000 \mathrm{hPa}$ and $500 \mathrm{hPa}$ levels $\left(\mathrm{LH}_{1000}-\mathrm{LH}_{500}\right)$ over Dhaka at 0000 UTC,

$\mathrm{X}_{21}=24$-hour - change in geopotential height at $925 \mathrm{hPa}$ over Dhaka at 0000 UTC $\left(\Delta Z_{24}\right)$ at $925 \mathrm{hPa}$,

$\mathrm{X}_{22}=24$-hour - change in geopotential height over Dhaka at $0000 \mathrm{UTC}$ at $1000 \mathrm{hPa}$ $\left(\Delta Z_{24}\right)$ at $1000 \mathrm{hPa}$,

$\mathrm{X}_{23}=$ Zonal wind component at $850 \mathrm{hPa}\left(\mathrm{u}_{850}\right)$ over Dhaka at $0000 \mathrm{UTC}$,

$\mathrm{X}_{24}=$ Meridional wind component at $850 \mathrm{hPa}\left(\mathrm{v}_{850}\right)$ over Dhaka at $0000 \mathrm{UTC}$,

$\mathrm{X}_{25}=$ Zonal wind component at $200 \mathrm{hPa}\left(\mathrm{u}_{200}\right)$ over Dhaka at $0000 \mathrm{UTC}$,

$\mathrm{X}_{26}=$ Meridional wind component at $200 \mathrm{hPa}\left(\mathrm{v}_{200}\right)$ over Dhaka at $0000 \mathrm{UTC}$,

$\mathrm{X}_{27}=$ Wind speed at $200 \mathrm{hPa}\left[\left(\mathrm{u}_{200}^{2}+\mathrm{v}^{2}{ }_{200}\right)^{0.5}\right]$ over Dhaka at $0000 \mathrm{UTC}$,

$\mathrm{X}_{28}=$ Wind speed at $700 \mathrm{hPa}\left(\mathrm{V}_{700}\right.$ in $\left.\mathrm{km} / \mathrm{hr}\right)$ over Dhaka at $0000 \mathrm{UTC}$,

$\mathrm{X}_{29}=$ Wind speed at $500 \mathrm{hPa}\left(\mathrm{V}_{500} \mathrm{in} \mathrm{km} / \mathrm{hr}\right)$ over Dhaka at $0000 \mathrm{UTC}$,

$\mathrm{X}_{30}=$ Wind speed at $300 \mathrm{hPa}\left(\mathrm{V}_{300} \mathrm{in} \mathrm{km} / \mathrm{hr}\right)$ over Dhaka at $0000 \mathrm{UTC}$,

$\mathrm{X}_{31}=$ Day's maximum upper air wind speed in $\mathrm{km} / \mathrm{hr}\left(\mathrm{V}_{\operatorname{maxUpper}}\right)$ over Dhaka at 0000 UTC,

$\mathrm{X}_{32}=$ Temperature difference between 500 and $200 \mathrm{hPa}\left(\mathrm{T}_{500}-\mathrm{T}_{200}\right)$ over Dhaka at 0000 UTC,

$\mathrm{X}_{33}=$ Dew point depression $\left(\mathrm{T}-\mathrm{T}_{\mathrm{d}}\right)$ at $1000 \mathrm{hPa}$ over Dhaka at $0000 \mathrm{UTC}$,

$\mathrm{X}_{34}=$ Modified Energy Index (MEI) over Dhaka at 0000 UTC,

$\mathrm{X}_{35}=$ Specific humidity $q_{500}$ at $500 \mathrm{hPa}$ level over Dhaka at $0000 \mathrm{UTC}$,

$\mathrm{X}_{36}=24$-hour pressure change at Dhaka at 0000 UTC $\left(\Delta P_{24}\right)$ over Dhaka at 0000 UTC, $a_{1}, a_{2}, a_{3}, \ldots \ldots \ldots \ldots \ldots a_{n}$ are regression co-efficients.

After obtaining the multiple regression equation for MWS associated with nor'westers, values of the MWS have been computed. The scatter diagrams for the computed MWS and the actual MWS have been prepared to obtain the values of $\mathrm{R}^{2}$. Then the significance test has been made with the help of F-distribution (Makridakis et al. 1983, Alder and Roessler 1964).

$$
F=\frac{R^{2}(N-k)}{\left(1-R^{2}\right)(k-1)}
$$

where $\mathrm{N}$ is the number of observations and $\mathrm{k}$ is the number of regressors. If the calculated value of $\mathrm{F}$ is greater than the theoretical value at certain significance level $(0.05$ or 0.01 i.e., $95 \%$ or $99 \%$ significance level) then $\mathrm{R}^{2}$ is taken as significant at that level.

The standard error of estimate (SEE) between the actual data and the estimated values has been computed with the help of the equation: 


$$
S E E=\sqrt{\frac{\left(Y-Y_{e}\right)^{2}}{N}}
$$

where, $\mathrm{Y}$ is the actual value, $\mathrm{Y}_{\mathrm{e}}$ is the computed value.

\section{RESULTS AND DISCUSSION}

The frequency distribution of MWS associated with nor'westers at Dhaka has been studied. The MWS and rainfall associated with nor'westers at Dhaka have been correlated with different parameters using rawinsonde data at 0000 UTC over Dhaka as described in methodology and a number of experiments have been conducted to find out an empirical formula for forecasting the MWS and rainfall associated nor'westers. Some of the results are described in the following sub sections.

Table 1. Frequency distribution of maximum wind speed associated with nor'westers/ thunderstorms at Dhaka.

\begin{tabular}{cc}
\hline Range $(\mathrm{km} / \mathrm{hr})$ & Frequency \\
\hline $30-40$ & 1 \\
$41-50$ & 4 \\
$51-60$ & 10 \\
$61-70$ & 9 \\
$71-80$ & 7 \\
$81-90$ & 7 \\
$91-100$ & 4 \\
$101-110$ & 6 \\
$111-120$ & 2 \\
$121-130$ & 1 \\
Total & 51 \\
\hline
\end{tabular}

The frequency of MWS associated with nor'westers at Dhaka during the period 1990 - 1995 is shown in Table 1. The table shows that maximum frequency of wind speed is 10 in the range of $50-60 \mathrm{~km} / \mathrm{hr}$. Most of the gusts/MWS at Dhaka occur in the range of 50 $110 \mathrm{~km} / \mathrm{hr}$.

\section{A. Experiment 1}

Multiple regressions of MWS recorded at the Storm Warning Centre (SWC) of BMD due to nor'westers have been made with 10 parameters and the result is given by the following equation:

$$
\begin{aligned}
V_{E x p-1}^{\max }= & -375.61-1.6615 X_{5}+1.1208 X_{8}-12.953 X_{11}+17.94 X_{12}+0.8505 X_{13}-0.03698 X_{15} \\
& +306.65 X_{16}+0.41807 X_{20}+0.41807 X_{23}+0.14943 X_{25}-0.19784 X_{32}
\end{aligned}
$$


The correlation coefficient is 0.5264 and the F-value is $1.53\left(\mathrm{~F}_{0.95}=2.08\right.$ for $\left.\mathrm{df}(10,40)\right)$, which is not statistically significant. The SEE is $17.91 \mathrm{~km} / \mathrm{hr}$. The variation of the actual MWS and the computed MWS is shown in Fig. 1. It is seen from the Fig. 1 that the variation of computed MWS has some similarity in many cases.

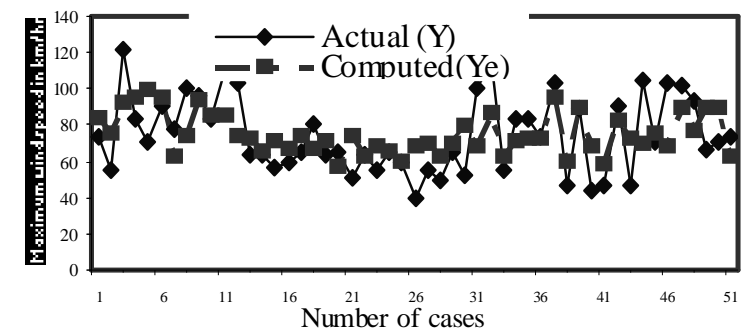

Fig. 1. Comparison of peak gust associated with nor'westers over Dhaka and the peak gust computed from developed multiple regression model (Experiment 1).

\section{B. Experiment 2}

By this experiment, multiple regressions of MWS recorded at the SWC of BMD due to nor'westers have been made with 20 parameters and the result is given by the following equation:

$$
\begin{aligned}
V_{E x p-2}^{\max }= & -299.12-1.4485 X_{5}+1.4192 X_{8}-9.3787 X_{11}+15.343 X_{12}-0.46988 X_{14}-0.02678 X_{15} \\
& +244.93 X_{16}+0.78063 X_{20}+0.26462 X_{21}-0.22429 X_{22}+0.52926 X_{23}-0.22914 X_{24} \\
& +0.55434 X_{25}-0.46351 X_{27}-0.13369 X_{28}+0.03405 X_{29}-0.03913 X_{30}+0.0207 X_{31} \\
& -0.359 X_{32}-2.1434 X_{33}
\end{aligned}
$$

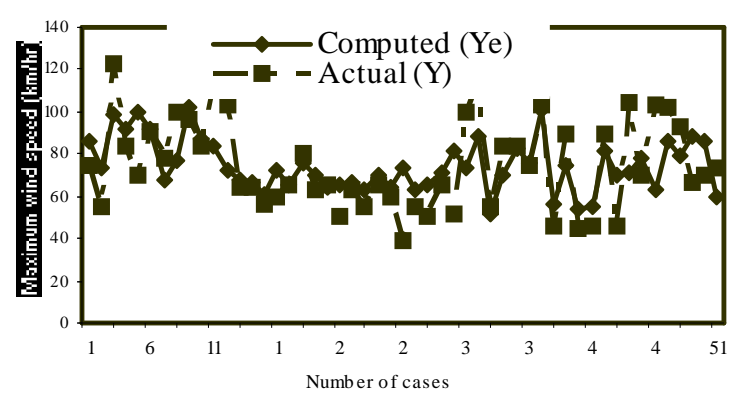

Fig. 2. Comparison of peak gust associated with nor'westers over Dhaka and the peak gust computed from developed multiple regression model (Experiment 2).

The correlation coefficient is 0.59144 and the F-value is 0.81 , which is $\left(\mathrm{F}_{0.95}=1.93\right.$ with df $(19,31)$ ) not statistically significant. The SEE is $16.99 \mathrm{~km} / \mathrm{hr}$. However, the result is encouraging. The variation of the actual MWS and the computed MWS is shown in Fig. 2. The figure shows that the pattern of the variation of actual and computed MWS is almost the same in most of the cases. 


\section{Experiment 3}

Twenty four parameters derived from the rawinsonde data and surface data have been correlated with MWS associated with nor'westers. The multiple regression equation obtained for the maximum gusty wind speed associated with nor'westers by experiment 3 is:

$$
\begin{aligned}
V_{E x p-3}^{M a x}= & -286.28-1.7752 X_{5}-0.0081 X_{6}-0.2233 X_{7}+1.4652 X_{8}+0.3815 X_{10}-9.4394 X_{11} \\
& +15.124 X_{12}-0.4852 X_{14}-0.0224 X_{15}+237.26 X_{16}+0.9045 X_{20}+0.2735 X_{21} \\
& -0.2191 X_{22}+0.5003 X_{23}-0.2558 X_{24}+0.5373 X_{25}-0.00232 X_{26}-0.4298 X_{27} \\
& -0.1014 X_{28}+0.0264 X_{29}-0.03397 X_{30}-0.3723 X_{31}-2.0172 X_{32}+0.0577 X_{36}
\end{aligned}
$$

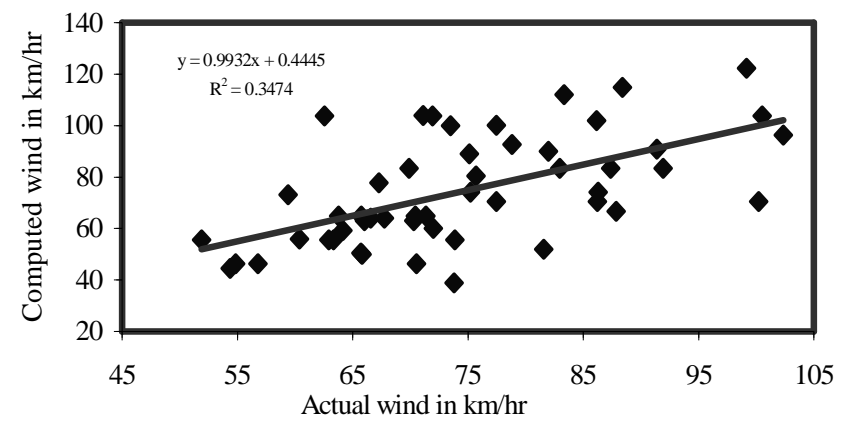

Fig. 3. Scatter diagram between actual and computed maximum wind speeds (Experiment 1).

where, $V_{E x p-3}^{M a x}$ is the computed maximum gusty wind speed in experiment 3 . The correlation coefficient is $0.59102\left[\mathrm{~F}_{\mathrm{cal}}=0.58, \mathrm{~F}_{0.95}=1.95\right.$, df $\left.(24,26)\right]$ and is not statistically significant.

\section{Experiment 4}

Only 7 parameters have been correlated with the MWS associated with nor'westers. The multiple regression equation obtained for the maximum gusty wind speed associated with nor'westers in experiment 4 is:

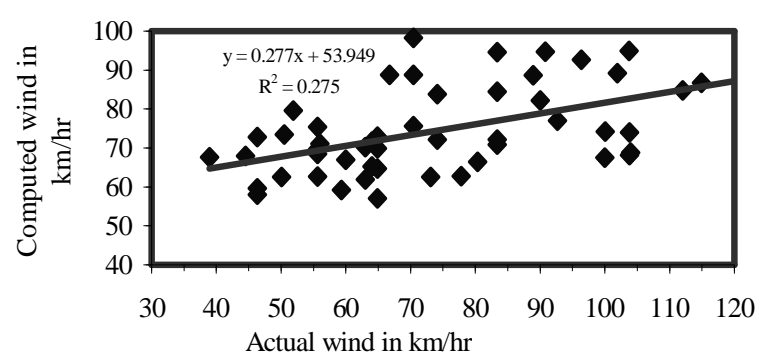

Fig. 4. Scatter diagram between actual and computed maximum wind speeds (Experiment 2). 


$$
\begin{aligned}
V_{E x p-4}^{M a x}= & -533.38-1.5239 X_{5}+0.55567 X_{8}-19.392 X_{11}+24.89 X_{12}+0.64226 X_{20} \\
& +467.46 X_{16}-0.44853 X_{24}
\end{aligned}
$$

where, $V_{E x p-4}^{M a x}$ is the computed maximum gusty wind speed in experiment 4 . The correlation coefficient is $0.49325\left[\mathrm{~F}_{\mathrm{cal}}=1.98, \mathrm{~F}_{0.95}=2.23\right.$, df $\left.(7,43)\right]$, which is not significant statistically.

Table 2. Comparison between the actual maximum wind speed (MWS) at Dhaka and the computed MWS by linear multiple regression models (Expts. 1, 2, 3 and 4) based on

\begin{tabular}{|c|c|c|c|c|c|c|}
\hline \multirow{2}{*}{ Dates } & \multirow{2}{*}{$\begin{array}{l}\text { Actual } \\
\text { MWS }\end{array}$} & \multicolumn{4}{|c|}{ Computed MWS } & \multirow{2}{*}{ SEE } \\
\hline & & Expt. 1 & Expt. 2 & Expt. 3 & Expt. 4 & \\
\hline 09-04-2005 & 46 & 60.92 & 60.92 & 60.92 & 51.740 & Expt. 1 \\
\hline 20-04-2005 & 83 & 145.88 & 145.88 & 145.88 & ------ & \pm 21.03 \\
\hline 24-04-2005 & 41 & 65.80 & 65.80 & 65.80 & 66.998 & Expt. 2 \\
\hline 25-04-2005 & 96 & 80.17 & 80.17 & 80.17 & 85.047 & \pm 15.93 \\
\hline 26-04-2005 & 48 & 78.17 & 78.17 & 78.17 & 74.588 & Expt. 3 \\
\hline 27-04-2005 & 87 & 88.53 & 88.53 & 88.53 & 79.070 & \pm 14.87 \\
\hline 29-04-2005 & 56 & 76.92 & 76.92 & 76.92 & 71.246 & \\
\hline 05-05-2005 & 56 & 67.73 & 67.73 & 67.73 & 63.907 & Expt. 4 \\
\hline 20-05-2005 & 59 & 62.96 & 62.96 & 62.96 & 59.090 & \pm 13.61 \\
\hline 22-05-2005 & 87 & 93.00 & 93.00 & 93.00 & 92.396 & \\
\hline
\end{tabular}
random data during March - May, 2005.

The linear multiple regression equations 1, 2, 3 and 4 developed for the maximum gusty wind speed have been used to compute the maximum gusty wind speed using the different parameters derived from the rawinsonde data and MSL pressure over Dhaka for the pre-monsoon season of 2005. The computed maximum gusty wind speed at Dhaka and the actual maximum gusty wind speed at Dhaka have been compared and are given in Table 2. The linear multiple regression equations 1, 2, 3 and 4 for maximum gusty wind speed have also been used to compute the maximum gusty wind speed using continuous data over Dhaka during 1 - 16 May, 2005. The computed maximum gusty wind speed and the actual maximum gusty/maximum wind speed at Dhaka have been compared and are given in Table 3.

It can be seen from the Table 2 that the results are encouraging with SEE \pm 21.03 , $\pm 15.93, \pm 14.87$ and $\pm 13.61 \mathrm{kph}$ for the regression equations $1,2,3$ and 4 , respectively. The SEE in experiments 3 and 4 are appreciably smaller. The regression equation 4 is more acceptable.

Table 3 also shows that the SEE $\pm 16.81, \pm 17.97, \pm 16.18$ and $\pm 20.11 \mathrm{kph}$ for the regression equations 1, 2, 3 and 4, respectively for continuous data during 1 - 16 May, 2005. The equations give the indications for the occurrence of gusty wind, though the SEE is larger. 
Linear multiple regression equations have been developed for the prediction of 24 hrs country-averaged rainfall (CAR), maximum $24 \mathrm{hrs}$ rainfall in Bangladesh and $24 \mathrm{hrs}$ rainfall over Dhaka using different meteorological parameters and rainfall due to nor'westers.

Table 3. Comparison between the actual MWS at Dhaka and the computed MWS by linear multiple regression models (Expt. 1, 2, 3 and 4) based on continuous data during 1 - 16 May, 2005.

\begin{tabular}{|c|c|c|c|c|c|c|c|}
\hline \multirow{2}{*}{ Dates } & \multirow{2}{*}{$\begin{array}{l}\text { Actual } \\
\text { MWS }\end{array}$} & \multirow{2}{*}{$\begin{array}{l}\text { MWS at other } \\
\text { places }\end{array}$} & \multicolumn{4}{|c|}{ Computed MWS } & \multirow{2}{*}{ SEE } \\
\hline & & & Expt. 1 & Expt. 2 & Expt. 3 & Expt. 4 & \\
\hline 01-05-2005 & 46 & & 64.95 & 59.38 & 50.42 & 70.54 & Expt. 1 \\
\hline 02-05-2005 & 9 & & 46.38 & 43.20 & 35.62 & 58.87 & \pm 16.81 \\
\hline 03-05-2005 & 13 & & 63.02 & 52.31 & 19.37 & 66.05 & \\
\hline 04-05-2005 & 41 & Bogra: 78 & 76.40 & 63.96 & 49.74 & 75.74 & Expt. 2 \\
\hline 05-05-2005 & 56 & Khepupara: 109 & 67.73 & 61.09 & 58.76 & 63.91 & \pm 17.97 \\
\hline 06-05-2005 & 11 & Rangpur: 63 & 58.13 & 56.77 & 27.67 & 62.91 & \\
\hline 07-05-2005 & 6 & & 77.50 & 64.71 & 29.71 & 96.57 & Expt. 3 \\
\hline 08-05-2005 & 13 & Sitakundu: 61 & 62.76 & 54.08 & 44.49 & 67.06 & \pm 16.18 \\
\hline 09-05-2005 & 9 & Chittagonj: 45 & 56.71 & 53.07 & 45.50 & 61.27 & \\
\hline $10-05-2005$ & 13 & Sylhet: 78 & 61.03 & 51.73 & 52.81 & 72.35 & Expt. 4 \\
\hline 11-05-2005 & 13 & Sylhet: 55 & 78.07 & 68.49 & 65.23 & 83.51 & \pm 20.11 \\
\hline $12-05-2005$ & 46 & & 88.05 & 61.83 & 77.79 & 91.17 & \\
\hline 13-05-2005 & 111 & & $*$ & $*$ & $*$ & & \\
\hline $14-05-2005$ & 13 & Sylhet: 56 & 66.24 & 42.60 & 34.55 & 68.65 & \\
\hline $15-05-2005$ & 17 & Sylhet: 41 & 84.80 & 81.10 & 53.14 & 88.38 & \\
\hline $16-05-2005$ & 50 & Sylhet: 48 & 79.24 & 62.11 & 45.77 & 82.36 & \\
\hline
\end{tabular}

\section{A. Linear multiple regression equations for the country-averaged 24 hrs rainfall}

The linear multiple regression equation for the $24 \mathrm{hrs}$ CAR with 15 different parameters is given below:

$$
\begin{aligned}
R_{\max }= & -47.593+0.30343 X_{1}-2.0397 X_{2}+0.7502 X_{3}+0.15477 X_{4}-0.01198 X_{9}+0.3378 X_{10} \\
& -0.15745 X_{11}+1.15487 X_{12}+0.25286 X_{13}-0.26142 X_{14}+0.0288 X_{15}+0.31651 X_{17} \\
& -1.0138 X_{18}+3.9788 X_{19}+0.9899 X_{34}
\end{aligned}
$$

where, $\mathrm{R}_{\mathrm{CA}}$ is the country-averaged $24 \mathrm{hrs}$ rainfall over Bangladesh. The correlation coefficient is 0.62777 , which is significant at $100 \%$ level of significance $\left[\mathrm{F}_{\text {cal }}=3.86, \mathrm{~F}=\right.$ 2.27 , df $(15,89)]$. The correlation coefficient is statistically significant at $100 \%$ level.

The linear multiple regression equation 5 for the $24 \mathrm{hrs}$ CAR has been used to compute the CAR using the different parameters derived from the rawinsonde data for 
the period 1 - 16 May, 2005 and the results are given in Table 6. The results indicate overestimation of CAR but the SEE is \pm 16.55 . This may due to the fact that upper air data over Dhaka has been used but nor'westers did not occur everyday over Dhaka during the period and so the rainfall was zero at Dhaka on those days.

Table 6. Comparison between the actual and the computed CAR using equations 5, 8 and 9 based on the data during 1 - 16 May, 2005.

\begin{tabular}{cccccc}
\hline \multirow{2}{*}{ Dates } & \multirow{2}{*}{ Actual CAR } & \multicolumn{3}{c}{ Computed CAR } & \multirow{2}{*}{ SEE } \\
\cline { 2 - 5 } $01-05-2005$ & 1.471 & 49.929 & 8.8191 & 7.91 & Eq. 5: \\
$02-05-2005$ & 1.316 & 45.556 & 8.849 & 6.094 & \pm 16.549 \\
$03-05-2005$ & 2.779 & 46.671 & 8.970 & 5.828 & \\
$04-05-2005$ & 7.559 & 10.885 & 10.714 & 8.308 & Eq. 8: \\
$05-05-2005$ & 21.265 & 19.827 & 9.196 & 10.862 & \pm 4.910 \\
$06-05-2005$ & 6.287 & 44.919 & 8.332 & 6.045 & \\
$07-05-2005$ & 6.221 & 40.397 & 7.324 & 3.419 & Eq. 9: \\
$08-05-2005$ & 12.779 & 52.032 & 11.694 & 10.373 & \pm 5.821 \\
$09-05-2005$ & 6.007 & 44.466 & 9.776 & 6.710 & \\
$10-05-2005$ & 6.765 & 56.769 & 13.595 & 12.324 & \\
$11-05-2005$ & 1.412 & 49.524 & 10.462 & 11.561 & \\
$12-05-2005$ & 3.860 & 48.505 & 7.860 & 12.063 & \\
$13-05-2005$ & 5.029 & $*$ & 7.552 & $*$ & \\
$14-05-2005$ & 2.154 & 58.444 & 6.220 & 13.104 & \\
$15-05-2005$ & 6.037 & 57.352 & 7.989 & 14.554 & \\
$16-05-2005$ & 4.022 & 51.711 & 10.131 & 11.472 & \\
\hline
\end{tabular}

B. Linear multiple regression equations for the $24 \mathrm{hrs}$ maximum rainfall in Bangladesh

Fifteen parameters have been correlated with $24 \mathrm{hrs}$ maximum rainfall in Bangladesh. The linear multiple regression equation for the $24 \mathrm{hrs}$ maximum rainfall in Bangladesh with different parameters is given below:

$$
\begin{aligned}
R_{\max }= & -124.31+1.2214 X_{1}-6.3362 X_{2}+1.3422 X_{3}-2.3201 X_{4}+0.03735 X_{9} \\
& +1.543 X_{10}-0.7697 X_{11}+2.6342 X_{12}+1.7561 X_{13}+1.1728 X_{14}+ \\
& 0.01551 X_{15}+1.1452 X_{17}-2.388 X_{18}+2.6175 X_{34}+12.985 X_{35}
\end{aligned}
$$

where, $R_{\mathrm{Max}}$ is the $24 \mathrm{hrs}$ maximum rainfall in Bangladesh. The correlation coefficient is 0.56125 , which is significant at $100 \%$ level of significance $\left[F_{\text {cal }}=2.73, F=2.27\right.$, df $(15$, 89)]. The correlation coefficient is statistically significant at $100 \%$ level. 
The linear multiple regression equation 6 developed for the 24 hrs maximum rainfall over Bangladesh has been used to compute the maximum rainfall using the different parameters derived from the rawinsonde data for the period 1 - 16 May, 2005 and the results are given in Table 7 . Though the SEE, \pm 18.749 , is larger, the results are encouraging.

Table 7. Comparison between the actual 24 hrs rainfall at Dhaka $\left(\mathbf{R}_{\mathrm{Dh} a}\right)$ and maximum rainfall in Bangladesh $\left(\mathbf{R}_{\max }\right)$ with the computed rainfall by linear multiple regression model based on the data during 1 - 16 May, 2005.

\begin{tabular}{|c|c|c|c|c|c|c|c|}
\hline \multirow[b]{2}{*}{ Dates } & \multirow{2}{*}{$\begin{array}{c}\text { Actual } \\
24 \text { hrs } \\
\mathrm{R}_{\text {Dha }}\end{array}$} & \multicolumn{2}{|c|}{ Computed 24-h R } & \multirow{2}{*}{$\begin{array}{c}\text { Actual } \\
24 \mathrm{hrs} \\
\mathrm{R}_{\max }\end{array}$} & \multicolumn{2}{|c|}{ Computed 24 hrs $R_{\max }$} & \multirow[b]{2}{*}{ SEE } \\
\hline & & Eq. 7 & Eq. 10 & & Eq. 6 & Eq. 11 & \\
\hline 01-05-2005 & 0 & 17.774 & 13.041 & 23 & 51.184 & 47.826 & Eq. $6: \pm$ \\
\hline 02-05-2005 & 0 & 7.835 & 13.112 & 20 & 66.829 & 55.982 & 18.749 \\
\hline 03-05-2005 & 0 & 2.785 & 13.400 & 41 & 52.282 & 57.280 & \\
\hline 04-05-2005 & 6 & 27.870 & 17.536 & 45 & 70.602 & 55.072 & Eq. $7: \pm$ \\
\hline 05-05-2005 & 16 & 28.560 & 13.934 & 64 & 79.090 & 51.932 & 686 \\
\hline 06-05-2005 & 0.25 & 3.852 & 11.885 & 67 & 57.742 & 53.577 & \\
\hline 07-05-2005 & 0 & 3.681 & 9.492 & 75 & 53.115 & 41.881 & Eq. 10: \\
\hline 08-05-2005 & 7 & 21.867 & 19.862 & 85 & 77.259 & 64.173 & \pm 11.321 \\
\hline 09-05-2005 & 10 & 11.456 & 15.312 & 45 & 60.781 & 51.898 & \\
\hline $10-05-2005$ & 0 & 28.600 & 24.374 & 52 & 90.007 & 81.068 & Eq. 11: \\
\hline $11-05-2005$ & 0 & 20.793 & 16.938 & 25 & 50.745 & 50.008 & \pm 20.358 \\
\hline $12-05-2005$ & 8 & 16.418 & 10.765 & 23 & 42.798 & 42.758 & \\
\hline $13-05-2005$ & 38 & $*$ & 10.035 & 64 & $*$ & $*$ & \\
\hline $14-05-2005$ & 0 & 16.677 & 6.873 & 29 & 64.481 & 55.630 & \\
\hline $15-05-2005$ & 0.25 & 24.409 & 11.071 & 53 & 59.120 & 55.239 & \\
\hline $16-05-2005$ & 10 & 59.759 & 16.155 & 41 & 56.277 & 55.009 & \\
\hline
\end{tabular}

\section{Linear multiple regression equations for the $24 \mathrm{hrs}$ rainfall at Dhaka}

The linear multiple regression equation for the 24 hrs rainfall at Dhaka with 15 different parameters is given below:

$$
\begin{aligned}
R_{\text {Dha }}= & -331.26+0.56864 X_{1}-2.6421 X_{2}+4.8911 X_{3}+1.0439 X_{4}-0.053 X_{9}+7.13248 X_{10} \\
& +3.1014 X_{11}+2.4528 X_{12}-1.422 X_{13}-0.85393 X_{14}+0.09023 X_{15}+0.81183 X_{17} \\
& -1.074 X_{18}+19.79 X_{19}+1.0352 X_{34}
\end{aligned}
$$

where, $\mathrm{R}_{\mathrm{Dha}}$ is the $24 \mathrm{hrs}$ rainfall at Dhaka. The correlation coefficient is 0.56391 , which is significant at $100 \%$ level of significance $\left[F_{c a l}=2.77, F=2.27\right.$, df $\left.(15,89)\right]$. The correlation coefficient is statistically significant at $100 \%$ level.

The linear multiple regression equation 7 developed for the $24 \mathrm{hrs}$ rainfall at Dhaka has been used to compute the maximum rainfall using the different parameters derived 
from the rawinsonde data over Dhaka for the pre-monsoon season of 2005. The computed 24 hrs rainfall at Dhaka and the actual 24 hrs rainfall at Dhaka have been compared and is given in Table 8 .

Table 8. Comparison between the actual 24 hrs rainfall at Dhaka $\left(\mathbf{R}_{\mathrm{Dha}}\right)$ and the computed rainfall by linear multiple regression model based on random data during March-May 2005.

\begin{tabular}{lccc}
\hline Dates & Actual 24 hrs $\mathrm{R}_{\text {Dha }}$ & Computed 24 hrs $\mathrm{R}_{\text {Dha }}$ & SEE \\
\hline $20-04-2005$ & 1 & 0 & \pm 17.6826 \\
$23-04-2005$ & 0.25 & 10.8692 & \\
$25-04-2005$ & 23 & 56.0260 & \\
$26-04-2005$ & 45 & 23.1427 & \\
$04-05-2005$ & 6 & 27.8698 & \\
$12-05-2005$ & 8 & 7.14557 & \\
$16-05-2005$ & 10 & 20.1383 & \\
$19-05-2005$ & 38 & 28.6176 & \\
$21-05-2005$ & 28 & 40.2688 & \\
$22-05-2005$ & 72 & 51.3112 & \\
\hline
\end{tabular}

It can be seen from the Table 8 that the results are encouraging with SEE \pm 17.683 $\mathrm{mm}$ for the regression equation 7. Though the SEE is larger, the correlation coefficient is statistically significant at $100 \%$ level. Regression equation 7 has been used to compute 24 hrs rainfall at Dhaka using the different parameters derived from the rawindsonde data for the period 1 - 16 May, 2005 and the results are given in Table 7. The equation overestimates the rainfall at Dhaka. This may be due to the fact that nor'westers did not occur over Dhaka everyday and so the rainfall was zero at Dhaka on many days.

\section{Simple regression equations for the CAR in Bangladesh}

In case of verification of the regression equations for rainfall, it has been found that there are trace amount of rainfall on one or two days. Trace amount of rainfall is defined as the rainfall below $0.5 \mathrm{~mm}$. In this study, $0.25 \mathrm{~mm}$ is taken as the trace amount of rainfall. Based on the data during the pre-monsoon season of 1990-95, the regression equations developed for the CAR with precipitable water and MSWI are given below:

$$
\begin{aligned}
& R_{C A}=0.306 \times W-1.3696 \\
& R_{C A}=0.0207 \times M S W I-0.1335
\end{aligned}
$$

where, $\mathrm{R}_{\mathrm{CA}}$ is the 24 hours CAR over Bangladesh, $\mathrm{W}$ is the precipitable water content of the troposphere at 0000 UTC over Dhaka and MSWI is the Modified SWEAT Index. The 
correlation coefficients are $0.24915\left(\mathrm{t}_{\mathrm{cal}}=2.64837, \mathrm{n}=108\right)$ and $0.30425\left(\mathrm{t}_{\mathrm{cal}}=3.28832\right.$, $\mathrm{n}=108$ ), which are significant at $95 \%$ level of significance. Table 4 gives the comparison between the actual and the computed CAR.

Table 9. Comparison between the actual Country average rainfall (CAR) and the computed CAR based on the data during different dates on March - May, 2005.

\begin{tabular}{ccccc}
\hline \multirow{2}{*}{ Dates } & Actual CAR & \multicolumn{2}{c}{ Computed CAR } & \multirow{2}{*}{ SEE } \\
\cline { 3 - 4 } & & Eq. 8 & Eq. 9 & \\
\hline 09-04-2005 & 5.45 & 7.29 & 9.57 & \\
$23-04-2005$ & 4.66 & 8.29 & 3.49 & Using Eq. 8: \\
$24-04-2005$ & 3.77 & 8.66 & 8.6 & \pm 3.17845 \\
$25-04-2005$ & 4.27 & 9.45 & 6.71 & \\
$27-04-2005$ & 7.45 & 10.08 & 10.27 & \\
$29-04-2005$ & 11.02 & 9.74 & 10.93 & Using Eq. 9: \\
$30-04-2005$ & 5.78 & 7.82 & 15.21 & \\
$12-05-2005$ & 3.86 & 7.86 & 9.73266 & \\
$20-05-2005$ & 7.54 & 10.11 & 9.22 & \\
$21-05-2005$ & 9.41 & 10.79 & 13.77 & \\
$22-05-2005$ & 19.38 & 12.29 & 13.99 & \\
\hline
\end{tabular}

The table shows the encouraging results with SEE \pm 3.178 and $\pm 3.733 \mathrm{~mm}$ for the regression equations 8 and 9 , respectively. These equations can be used to predict country-averaged $24 \mathrm{hrs}$ rainfall associated with nor'westers. Using the data for the period 1 - 16 May, 2005 has also used the above equations to obtain CAR amount and the results are given in Table 9. The results are encouraging too with SEE \pm 4.910 and \pm 5.821 for the equations 8 and 9 , respectively.

E. Simple regression equations for the 24 hours rainfall at Dhaka and maximum rainfall in Bangladesh

The regression equations for the $24 \mathrm{hrs}$ rainfall at Dhaka and the maximum rainfall in Bangladesh with precipitable water and SWI are given below:

$$
\begin{aligned}
& R_{\text {Dha }}=0.7261 \times W-11.136 \\
& R_{\text {Max }}=0.0859 \times S W I+33.154
\end{aligned}
$$

where, $R_{D h a}$ is the 24 hrs rainfall at Dhaka, $R_{\text {Max }}$ is the 24 hours maximum rainfall in Bangladesh, W is the precipitable water content of the troposphere at 0000 UTC over Dhaka and SWI is the SWEAT Index. The correlation coefficients are $0.246601\left(\mathrm{t}_{\mathrm{cal}}=\right.$ 2.619817, $\mathrm{n}=108)$ and $0.29504\left(\mathrm{t}_{\mathrm{cal}}=3.17912, \mathrm{n}=108\right)$, which are significant at $95 \%$ 
level of significance. Table 10 gives the comparison between the actual 24 hours rainfall at Dhaka and maximum 24 hours rainfall in Bangladesh and the computed rainfall.

The table shows the encouraging results with SEE \pm 12.3388 and $\pm 8.5680 \mathrm{~mm}$ for the regression equations 10 and 11, respectively. Though the SEE is a bit larger in case of 24 hrs rainfall at Dhaka, the correlation coefficient is statistically significant at $95 \%$ level. The SEE is significantly smaller in case of maximum rainfall in Bangladesh. These equations can be used to predict $24 \mathrm{hrs}$ rainfall at Dhaka and $24 \mathrm{hrs}$ maximum rainfall in Bangladesh associated with nor'westers.

Table 10. Comparison between the actual $24 \mathrm{hrs}$ rainfall at Dhaka $\mathbf{R}_{\text {Dha }}$ and maximum rainfall in Bangladesh $R_{\max }$ with the computed rainfall by linear multiple regression models based on random data during March - May, 2005.

\begin{tabular}{|c|c|c|c|c|c|c|c|}
\hline \multirow[t]{2}{*}{ Dates } & \multirow[t]{2}{*}{$\begin{array}{c}\text { Actual } \\
24 \text { hrs } \\
\mathrm{R}_{\text {Dha }}\end{array}$} & $\begin{array}{l}\text { Computed } \\
24 \text { hrs } R_{\text {Dha }}\end{array}$ & SEE & \multirow[t]{2}{*}{ Dates } & $\begin{array}{c}\text { Actual } 24 \text { hrs } \\
\mathrm{R}_{\max } \text { in } \\
\text { Bangladesh }\end{array}$ & $\begin{array}{c}\text { Computed } 24 \\
\text { hrs } \mathrm{R}_{\max } \text { in } \\
\text { Bangladesh }\end{array}$ & \multirow[t]{2}{*}{ SEE } \\
\hline & & \multicolumn{2}{|c|}{10} & & \multicolumn{2}{|c|}{11} & \\
\hline 03-04-2005 & 3 & 4.735 & \pm 12.339 & 09-04-2005 & 45 & 47.817 & \pm 8.568 \\
\hline 24-04-2005 & 6 & 12.659 & & 23-04-2005 & 44 & 43.720 & \\
\hline 25-04-2005 & 23 & 14.527 & & 26-04-2005 & 45 & 53.787 & \\
\hline 26-04-2005 & 45 & 17.196 & & 27-04-2005 & 61 & 59.439 & \\
\hline 29-04-2005 & 8 & 15.236 & & 29-04-2005 & 58 & 53.014 & \\
\hline 04-05-2005 & 6 & 17.536 & & 01-05-2005 & 23 & 47.826 & \\
\hline 05-05-2005 & 16 & 13.934 & & 04-05-2005 & 45 & 55.072 & \\
\hline $12-05-2005$ & 8 & 10.765 & & 19-05-2005 & 51 & 47.826 & \\
\hline $16-05-2005$ & 10 & 16.155 & & $22-05-2005$ & 75 & 73.072 & \\
\hline 19-05-2005 & 38 & 14.482 & & & & & \\
\hline $21-05-2005$ & 28 & 17.716 & & & & & \\
\hline
\end{tabular}

The above equations have also been used to obtain $24 \mathrm{hrs}$ rainfall at Dhaka and the maximum rainfall over Bangladesh by using the continuous data for the period 1 - 16 May 2005 and the results are given in Table 7. The SEE's are \pm 11.321 and \pm 20.358 for the equations 10 and 11, respectively. The values are larger and the equation 10 overestimates the rainfall at Dhaka.

The correlation between the computed MWS obtained by the empirical formula of Experiments 1 and 2 and the actual MWS associated with nor'westers has been made through scatter diagrams as shown in Figs. 3 and 4 . The $\mathrm{R}^{2}$ values are 0.275 and 0.3474 , which correspond to the F-values of 9.10344 and 12.77597, indicating statistically significance at $95 \%$ level. 


\section{CONCLUSIONS}

Based on the present study, the following conclusions can be drawn:

(i) The maximum frequency of wind speed is in the range of 50-60 km/hr and the frequency is 10 most of the gusts/MWS at Dhaka occurs in the range of 50-110 $\mathrm{km} / \mathrm{hr}$.

(ii) The proposed regression equations are useful in the estimation of maximum gusty wind speed associated with nor'westers in Bangladesh. Using them, the computed values of maximum gusty wind speed have statistically significant correlation with the actual maximum gusty wind speed and are comparable with the observed.

(iii) The multiple regression equations developed for the estimation of $24 \mathrm{hrs}$ CAR, $24 \mathrm{hrs}$ maximum rainfall in Bangladesh and the $24 \mathrm{hrs}$ rainfall at Dhaka are likely to be useful in the operational forecasting purposes.

(iv) The techniques identified for the occurrence of nor'westers will be useful for the operational Meteorologist in Bangladesh and provide better forecasting tool.

\section{ACKNOWLEDGMENTS}

Authors are thankful to the Director of Bangladesh Meteorological Department (BMD) for providing the relevant data for the study. Thanks are due also to Mr. Abdul Mannan, Assistant Meteorologist, Mr. S. M. Quamrul Hassan, Assistant Meteorologist and Mrs. Masuda Mohi, Teliprinter Operator of BMD for their help in the preliminary compilation of data.

\section{REFERENCES}

Alder, H.L. and E.B. Roessler. 1964. Introduction to Probability and Statistics, 3rd Edn., W.H. Freeman and Company, pp. 283-287.

Chowdhury, M.H.K. and S. Karmakar. 1986. Pre-monsoon Nor'westers in Bangladesh with case studies. Proceedings of the SAARC Seminar on Local Severe Storms, Bangladesh Met. Dept., pp. 147-166.

Darkow, G.L. 1968. The total energy environment of severe storms. J. Appl. Met. 7(2): 199- 205.

Das, R.C., A. A. Munim, Q. N. Begum and S. Karmakar. 1994. A Diagnostic study on some local severe storms over Bangladesh. J. Bangladesh Acad. Sci. 18(1): 81-92.

Faubush, E.J., R.C. Miller and L.G. Starrett. 1951. An empirical method for forecasting tornado development. Bull. Amer. Meteor. Soc. 32: 19.

Galway, J.G. 1956. The lifted Index as a predictor of latent instability. Bull. Amer. Meteor. Soc. 37: 528-529. 
Karmakar, S. and M. Alam. 2006. Instability of the Troposphere Associated with Thunderstorms/nor'westers over Bangladesh during the pre-monsoon season. Mausam 57(4): 629-638.

Karmakar, S. and M. Alam. 2007. Interrelation among different instability indices of the troposphere over Dhaka associated with thunderstorms/nor'westers over Bangladesh during the pre-monsoon season. Mausam 58(3): 361-368.

Makridakis, S., S.C. Wheelwright and V.E. Mcgee. 1983. Forecasting: Methods and Applications. 2nd Ed., John Willey \& Sons, New York. pp. 222-223.

Miller, R.C. 1967. Notes on analysis and severe storm forecasting procedures on Military Weather Warning Center. Technical Report 200, Air Weather Service (MAC), U.S.A., pp. 10.1-10.6.

Pendse, G.C., V.C. Bedekar and A.K. Banerjee. 1967. Thunder storms at Nagpur. India Met. Dep. Sci. Rep. 41: 1-6.

Showalter, A.K. 1953. Stability index for forecasting thunderstorms. Bull. Amer. Meteor. Soc. 34: 250-252.

(Received revised manuscript on 14 March, 2011) 